\title{
The Influence of Distance and Neighbourhood Surroundings on Children's Travel Mode to School
}

\author{
Stefan SCHABUS ${ }^{1}$, Melanie TOMINTZ ${ }^{1}$ and Jan RIGBY ${ }^{2}$ \\ ${ }^{1}$ Carinthia University of Applied Sciences,Villach/Austria · stefan.schabus@edu.fh-kaernten.ac.at \\ ${ }^{2}$ Centre for Health Geoinformatics, National University of Ireland, Maynooth/Ireland
}

This contribution was double-blind reviewed as full paper.

\begin{abstract}
Nowadays, the amount of physical activity undertaken by children of school age is decreasing. This is a major concern, as it is linked with growing levels of obesity. This puts children at risk of a number of subsequent health conditions, particularly diabetes. This paper analyses the influence of the school environment on children's physical activity. The travel mode to school and the distance each student travels to school are taken into account. The analysis draws upon a study carried out in a large number of schools in the Republic of Ireland (ROI) over the course of 3 years, the Children's Sport Participation and Physical Activity (CSPPA) Study. By combining the spatial distribution of the students' homes and information about the school environment, it was possible to analyse on walking and cycling time by calculating service areas. The results of the analysis illustrate that the distance has an influence on physical activity because students living within $2.4 \mathrm{~km}$ of the school are more likely to walk to school than students living further away. The analysis also explored the impact of negative environmental factors.
\end{abstract}

\section{Introduction}

The understanding of health benefits arising from physical activities has been increasing. Walking or cycling can contribute to increase the daily amount of physical activity. Physically active people reduce their risk of major diseases including diabetes, stroke and heart disease. Therefore, an adequate level of physical activity undertaken in earlier years is important in reducing the risk of several diseases and establishing a positive approach to exercise (JONES et al. 2010). However, the amount of physical activity undertaken by children is falling, beginning at least as young as at the age of six (MAFFEIS et al. 2007). The neighbourhood in which children live influences their levels of physical activity (CRAGGS et al. 2011).

This research was motivated by increasing levels of obesity, the decreasing levels of physical activity of children at school age and the high potential for physical activity within the school environment. The Children`s Sport Participation and Physical Activity Study (CSPPA) provided a rich data source. This research explores neighbourhood effects on the travel mode to school and insight into how to increase physically active travel modes to 
school considering distance, safety and the local neighbourhood. It explores the extent to which the distance to school influences the choice of travel mode and if the neighbourhood also influences the choice. The school environment comprises areas in the neighbourhood or community surroundings, places for walking or cycling in the neighbourhood and the sense of safety in the community as well as the travel mode to the school. To achieve the goal, three schools in Dublin were chosen for the spatial analysis. There has already been some analysis of the survey data (WoODS et al. 2010). However, because the researchers could not geocode individual students ' homes, no geographical analysis was possible. The challenging task of geocoding in Ireland was part of the analysis reported here.

The data required for the spatial analysis were: a validated data set of the CSPPA study answers; the geocoded addresses of the students ' homes; and a road network which is the basis for the network analysis. Service areas visualise the area around a facility which is reachable within certain limitations. Maps were produced showing the influence of different aspects of the survey on the travel mode covered by the service areas. Such scenarios are helpful for decision makers to increase the number of students walking or cycling to school, through a safer neighbourhood or a better coverage/maintenance of pathways.

Summarising, the goal of this research is to perform a spatial analysis concerning the school environment, neighbourhood surroundings and the travel mode to school. Furthermore, the distances from the students' homes to the relevant school are taken into account. The paper establishes the theoretical background for the analysis, and outlines the original survey. Issues relating to geocoding are discussed, and results from the analysis are presented. Specific schools are not identified so that confidentiality can be maintained.

\section{Theoretical Background}

\subsection{Physical Activity, Health Benefits and the School Environment}

Physical activity is defined as bodily movement to increase energy by contraction of the muscles (WoODS et al. 2010). In the last few years, the understanding of health benefits arising from physically activity is increasing. Jones et al. (2010) show that physically active people reduce their risk of major diseases including diabetes, stroke and heart disease. Nowadays, the relationship between physical activity and health benefits is welldocumented well and must be taken into account for many types of diseases (BLAIR et al. 2001). Physical activity helps to strengthen self-discipline and can decrease vulnerability from mental health problems. Physical activity has the capability to enhance young people's mental wellbeing in association with improvements in their physical condition (WHITELAW et al. 2010). Hence physical activity has positive health benefits. Walking in the neighbourhood is a useful form of physical activity, especially for children who ideally should participate in some form of sport or physical activity for a minimum of one hour daily (SALMON \& TIMPERIO 2007). Therefore, the way to school and back home provides a good, and daily, opportunity. An important issue for walking or cycling as a physical activity is the availability of footpaths or cycling paths. There is a positive correlation between the access to these features in the neighbourhood and the amount of physical activity (OWEN et al. 2004).

The school environment is considered to be the children's surroundings in school, and their journey to and from home (O’MALLEY et al. 2009). Hence, the school environment includes 
the way to school as well as the school itself, alongside sport grounds, playgrounds and the class room. It is a place that naturally provides an opportunity to influence the daily physical activity of children of school age. The enormous influence of the school environment can be seen through physical education at school and further physical activity through an increasing amount of cycling or walking (O'MALLEY et al. 2009). Schools can help to increase the amount of physical activity children are involved in. This is possible through physical education lessons in the school, break times and the way to and from school (VERSTRAETE et al. 2006). In the CSPPA study the environment around school is considered through objective survey questions relating to places for walking or cycling in the neighbourhood, neighbourhood or community surroundings, neighbourhood satisfaction and the safety feeling in the neighbourhood of each student (WOODS et al. 2010).

\subsection{Children`s Sport Participation and Physical Activity Study (CSPPA)}

The CSPPA study is a volunteer multi-centre study carried out by Dublin City University (DCU), University College Cork (UCC)) and the University of Limerick (UL) (2012). The study was funded by the Irish Sports Council (ISC). It brings together different skills such as physical activity for health, sport and coaching studies and physical education. The information gathered provides evidence for the development of policy in sport, health and transport aimed at Irish children becoming more active in their free time. The four major objectives of the national CSPPA study are (WoODS et al. 2010).

- National database storing physical activity, physical education and sport participation levels of Irish children

- Fitness and health indices for the sample of the target group

- Analysing and gathering information about features influencing any kind of physical participation

- Insight and knowledge into surroundings for volunteering in youth sports and activity clubs

The study is a self-reporting survey which used students' objective measurements of physical activity to estimate the participation in physical education, extra-curricular and extra-school sport as well as physical activity. The survey was completed by children between the ages of 10 and 18 years. A total of 5.397 children completed the survey from 53 primary and 70 post-primary schools in Ireland. Some results were published elsewhere (Woods et al. 2010) but no spatial analysis was possible and therefore is the focus of our analysis.

\subsection{Geocoding and Address Problems in Ireland}

Geocoding entails the assigning of geographic coordinates such as latitude or longitude to a location. The location can be an address or any feature that can be positioned. Many countries have addressing systems which include a zip code, or postcode, which can be used for geocoding. A major problem in Ireland is that there are no official postcodes, and their absence is a considerable problem. The country is one of the few developed countries in the world dealing with this problem. A unique address or well-formed address exists in urban areas for nearly all of the Irish properties. In rural areas, however, there are often missing street names or numbers of houses. Sometimes there is the name of the house in the 
address and not the street or the house number, or the whole street has the same address The local postman/postwoman has the knowledge to deliver the post correctly but for people without this knowledge the address cannot be uniquely identified. Hence, the postcode problem is challenging for geocoding addresses and enabling the spatial component for further spatial analysis in case of the non-uniqueness (FOTHERINGHAM 2008).

Geocoding is important for GIS and spatial analysis but the lack of postcodes is not the only problem. Irish addresses are not formatted in a consistent way and the spelling is often a problem to identify the right address. A single different character can provide a wrong geocode. Additionally, the same town name can appear in many different Irish counties (LEWIS et al. 2006). There is a database, GeoDirectory, which provides accurate postal and geographic address information for Ireland. GeoDirectory is developed by Ordnance Survey Ireland (OSi) and An Post, the postal system, through combining their expertise and knowledge. The geographic coordinates are provided using Irish Grid or Irish Transverse Mercator (ITM) reference system. The accuracy of the geocodes depends on the level of positioning. There are three levels of how the data is collected: (i) the up-to-date map of the OSi, (ii) ortho-photography of OSi or (iii) personnel on the ground. The database supports the whole of Ireland that highlights the completeness of the addresses (FAHEY \& FINCH 2011). However, the problem remains in terms of linking an address to GeoDirectory.

\section{Data Processing and the Irish Geocoding Problem}

\subsection{Data Extraction and Preparation}

The spatial analysis is performed using data from three secondary schools in Dublin, selected to have differing neighbourhood characteristics. The data used for this spatial analysis can be separated into two parts. The first part provides the demographic information on the students. The second part outlines the survey answers of each participant in the CSPPA study. The survey contains questions relating to the neighbourhood or community surroundings including places for walking and cycling in the neighbourhood.

The demographic information holds the home address of the students, and a unique reference number, to link to the survey information. This file was used for the geocoding of the students' homes. Secondly, an SPSS file contained the coded responses to the main questionnaires, which produced approximately 400 attributes.

\subsection{Geocoding of the Extracted Addresses}

A geocoder, designed and developed by the Centre for Health Geoinformatics at the National University of Ireland, Maynooth, was used to automate the geocoding process. The geocoder takes as input a Comma Separated Values (CSV) file containing the address information and a unique identifier matching the address information in the original Microsoft Excel file. The geocoder processes each address record in the address file and attempts to match it to an entry in GeoDirectory, using the PostGIS extension for PostgreSQL. While not needed for this process, the PostGIS extension can aid in the visual geocoding process needed in some cases of address ambiguity. The output of the geocoder is a Microsoft Excel file containing the original CSV-file as one worksheet and three additional worksheets "Geocoded_Addresses", "Multiple_Matches" and "No_Match-ing_Records". 
The Excel worksheet "Geocoded_Addresses" contains all address records that were uniquely matched in GeoDirectory. For each of those records, the ID of the building and the coordinates are extracted from the GeoDirectory database. The Microsoft Excel worksheet "Multiple_Matches" stores original address records that have not been resolved to a single address in GeoDirectory. Example of these addresses may be where there is a missing house number or a where addresses could not be matched. If a specific searched house number is missing, a townland match or an Electoral District (ED) match is taken into account to geocode the address. (Townlands are a small geographic division or areal units spread out over the ROI and are based on historical landholdings (EVANS 2000)). EDs are a geographical subdivision for electoral constituencies in the ROI (DIAMOND \& PLATTNER 2006). The last worksheet "No_Matching_Records" in the Microsoft Excel file contains original records that did not match with GeoDirectory or records where there are problems with the address information.

The multiple match records are records where the address has matched to multiple entries in GeoDirectory. To overcome this issue, attempts are made to resolve address information to the smallest areal unit, if the address information cannot be found in GeoDirectory. First, a townland match is taken into account. That means the smallest geographic division unit is considered. If each address of the multiple answers is in the same townland, the average values of the easting and the northing are used for the geocoded coordinates. In case of multiple addresses in several townlands, the EDs are taken into account. Hence, the average values of the easting and northing corresponding to the selected ED are calculated. If there are multiple matches and not only one ED, it is necessary to look at the distribution of the results of the multiple matches and compare it to the study area. Then it is necessary to make a decision on the geocode visually, so this requires manual intervention. For these records an individual searching and validation process is necessary. This was also needed where no match could be found. Ultimately 324 addresses were processed.

Finally a road network was constructed to perform service area analysis using the software ArcGIS to calculate distances, the students' distribution and perform spatial visualisations.

\section{Results}

Firstly, the service areas for each school were calculated showing the area which is achievable through walking or cycling in a maximum time of 20 minutes. The walking speed was assumed to be 3 kilometres per hour and the cycling speed is assumed to be the double of the walking speed at 6 kilometres per hour. The walking speed is assumed being lower than the average of 4-5 kilometres per hour because students are often interacting socially as they walk. The areas with a maximum time of 20 minutes walking time to or from school are considered first. Over the three schools, there was a total of 92 students living within the calculated walking time to school. Of these, 9 students go to School A, 11 go to School B and 72 students go to School C. Of the 92 students within the maximum walking distance of 20 minutes, 86 answered that they usually walk to school; 4 usually cycle to school and 2 usually travel to school by a motorised travel mode. The 2 students using a motorised travel mode to school live in the service area of School B but go to School C. The reasons given for the motorised travel mode were that it was simply too far to walk or to cycle. 
Secondly, areas with a maximum cycling time of 20 minutes to or from the school were considered. There were 207 out of 324 students living within the calculated cycling time zone to school. Of these, 58 students go to School A 20 go to School B and 129 go to School C Of the 207 students within the maximum 20 minutes cycling distance, only 9 usually cycle to school. A high number, 176 students, walk to school and 22 of the 207 students usually travel to school using a motorised travel mode.

Table 1 shows a separation of the walking service area into intervals of 5 minutes relating to the 324 students and their school. Therefore, the service area is separated into 4 intervals. Each interval is arranged in 5 minutes of the walking service area of 20 minutes. It is defined that each student goes to school, which is used for the specific service area. Finally the table shows a total of each interval value. According to Salmon and Timperio (2007) the recommended daily amount of activity is 60 minutes and therefore the way to school and back can well contribute to reach the recommended daily activity amount.

Table 1: Physical active students separated through walking time and school

\begin{tabular}{lcccc}
\hline & $\begin{array}{l}\text { Students of } \\
\text { School A }\end{array}$ & $\begin{array}{l}\text { Students of } \\
\text { School B }\end{array}$ & $\begin{array}{l}\text { Students of } \\
\text { School c }\end{array}$ & $\begin{array}{l}\text { Physical } \\
\text { Active }\end{array}$ \\
\hline $\begin{array}{l}\text { Walking Time } \mathbf{0} \text { to 5 } \\
\text { minutes }\end{array}$ & 0 & 0 & 7 & 7 \\
$\begin{array}{l}\text { Walking Time >5 to 10 } \\
\text { minutes }\end{array}$ & 4 & 0 & 1 & 5 \\
$\begin{array}{l}\text { Walking Time >10 to 15 } \\
\text { minutes }\end{array}$ & 21 & 3 & 2 & 26 \\
$\begin{array}{l}\text { Walking Time >15 to 20 } \\
\text { minutes }\end{array}$ & 45 & 5 & 1 & 51 \\
\hline \begin{tabular}{l} 
Total values \\
\hline
\end{tabular} & 70 & 8 & 11 & 89 \\
\hline
\end{tabular}

Table 2 shows the separation of the cycling service area into 5-minute intervals relating to the 324 students and their school. Also here the 20 minutes are separated into 4 intervals for each interval of the cycling area. The students are listed as physically active and not physically active students. The abbreviation 'not p.a.' stands for not physically active students, according the students' questionnaire responses. The table shows that, unsureprisingly, the longer the time or the distance, the more students use a motorised travel mode to school. Within a possible cycling time of 10 minutes everybody uses a physical active travel mode such as either walking or cycling.

Table 2: Physical active students separated through cycling time and school

\begin{tabular}{|c|c|c|c|c|}
\hline & $\begin{array}{l}\text { Students of } \\
\text { School A }\end{array}$ & $\begin{array}{l}\text { Students of } \\
\text { School B }\end{array}$ & $\begin{array}{l}\text { Students of } \\
\text { School C }\end{array}$ & $\begin{array}{l}\text { Physical } \\
\text { Active }\end{array}$ \\
\hline $\begin{array}{l}\text { Cycling Time } 0 \text { to } 5 \\
\text { minutes }\end{array}$ & 4 & 0 & 9 & 13 \\
\hline $\begin{array}{l}\text { Cycling Time }>5 \text { to } 10 \\
\text { minutes }\end{array}$ & 57 & 10 & 2 & 69 \\
\hline $\begin{array}{l}\text { Cycling Time }>10 \text { to } 15 \\
\text { minutes }\end{array}$ & $45+6$ not p.a. & $23+3$ not p.a. & 0 & $68(77)$ \\
\hline $\begin{array}{l}\text { Cycling Time }>15 \text { to } 20 \\
\text { minutes }\end{array}$ & $13+2$ not p.a. & $17+5$ not p.a. & $5+2$ not p.a. & $35(44)$ \\
\hline Total values & $119+8$ not p.a. & $50+8$ not p.a. & $16+2$ not p.a. & 185 (203) \\
\hline
\end{tabular}


Finally the students using a motorised travel mode are compared with the responses relating to the quality of the neighbourhood or community surroundings and the places for walking or cycling. At School A the students with a motorised travel mode are fairly evenly distributed across the walking or cycling time zone. One area shows a close grouping of 4 students and was criticised for the absence of 'attractive buildings in the neighbourhood'. The students of School $\mathrm{C}$ using a motorised travel mode within the cycling or walking zone of 20 minutes are also distributed within the area. There are two 'clusters' with more students nearby. One is in an area reported as having few places for walking and cycling and the poor quality of neighbourhood surroundings (measures included having parked cars on both sides of the street, the appearance of litter and missing attractive buildings). For School B there were other reasons for the motorised travel mode with a small number of students commenting that it was a hilly area and further it is one of the few areas with no footpath.

Figure 1 shows the usefulness of GIS to map survey answers and detect 'clusters' of the survey answers to see where students strongly agree/disagree and somewhat agree/disagree. As a demonstration example two questions relating to places for walking in the area around School $\mathrm{C}$ are selected and visualised. The privacy of the students in this visualization is kept through the scale of the maps combined with the amount of students.

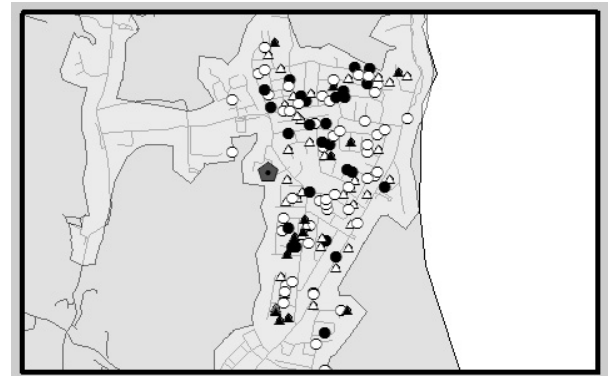

Footpaths are separated from the road/traffic by parked cars

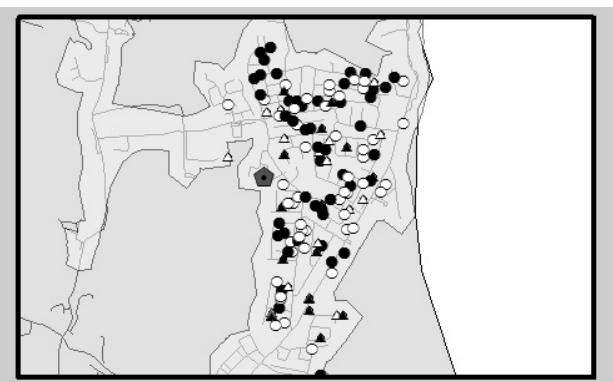

There is a grass/dirt strip that separates the streets from the footpaths.
Answers of the survey

- Strongly Disagree

$\triangle$ Somewhat Disagree
Somew hat Agree

- Strongly Agree

- Schools
Author: Stefan Schabus Date: 25.05.2012

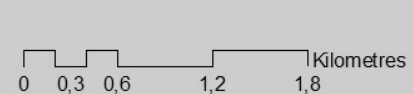

$\begin{array}{lll}0 & 0,3 & 0,6\end{array}$

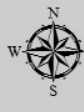

Fig. 1: Example questions relating to places for walking in the area around School C

The direct comparison of the answers is possible, and a visual comparison of areas can be used to try to identify why the respondents are not happy. This type of visualisation is especially valuable for further planning purposes of decision makers and policy makers. Areas with negative responses are shown in table 3 with a current picture of the criticised area. The table contains negative areas of all three schools. 
Table 3: $\quad$ Places for walking with many negatives responses

\begin{tabular}{|c|c|c|}
\hline Criticised Area & Picture of the Area & Description \\
\hline$\bullet$ & & $\begin{array}{l}\text { This criticised area is } \\
\text { situated near } \\
\text { SchoolC.The students } \\
\text { criticise that the } \\
\text { footpaths are not well } \\
\text { maintained there is no } \\
\text { grass strip between } \\
\text { the road and the } \\
\text { footpath. }\end{array}$ \\
\hline & & $\begin{array}{l}\text { This area is near } \\
\text { School B have The } \\
\text { students have } \\
\text { negative feeling about } \\
\text { cars parking on the } \\
\text { footpaths. Also the } \\
\text { maintenance is } \\
\text { criticised. It is one of } \\
\text { the main roads to the } \\
\text { school and very busy } \\
\text { with traffic. }\end{array}$ \\
\hline
\end{tabular}

The same analysis as for walking was done for cycling and it was found that only $10 \%$ (16 out of 164) from School C, 13\% (12 of 90) from School A but no student cycle from School B as either they live close to school and walk or they use a motorized travel transport mode. Reasons why students go by car or bus to school, although they are satisfied with cycle and footpaths in their neighbourhood and living within an assumed distance of a maximum of 2.41 kilometres ( 1.5 miles), were that it is "too early", which is a little surprising because the journey would not take long on foot or cycling or they say, surprisingly, that the school is too far away for them. Further, girls prefer getting to school by car but not by bus, because they must walk to the bus stop. Summarising, places for walking and cycling and the ease of access to them are clearly not the only reason why people chose a travel mode to school. Further reasons definitely include the distance to school and the neighbourhood and community surroundings. If a student lives near a school there is either the decision to go on foot or to go to school on bicycle. Many more students chose walking to school in case they are carrying bags, stating that it was easier on foot than cycling. Another reason for cycling depended on ease of access to a cycling path, because most of the students within the study area felt safe riding a bike in the neighbourhood. There were also outliers in the data, e.g. students who live near the school and get there by car because they can get a lift from their parents or a friend. That allows them to sleep longer and not to have to get up earlier or walk to school. Areas with many negative answers for walking-related questions had similar rates to the cycling questions. If students were not prepared to walk, they will not cycle. Summarising, the distance and the travelling time to school are the major aspects for the decision on the travel mode to school. The longer the travel time, particularly beyond $2.4 \mathrm{~km}$, the more and more students use a motorised travel mode. To increase 'walkability', aspects of these areas can be improved, e.g. street lighting, the quality of the footpaths, and safe crossing spaces between parked cars. For the students with a motorised travel mode it is often easy to get a lift and mostly by their family or friends. So it is important to educate family members to let the students walk or cycle to school. They can get a lift if they have heavy bags or many things to carry, but not every day. 


\section{Conclusion and Outlook}

This spatial analysis used individual survey responses from the CSPPA study to identify students' views on places for walking and cycling in the neighbourhood, neighbourhood or community surroundings, and linking these with the mode of travel to school. It has been shown that there is a new and successful approach for the geocoding of addresses in the ROI. The analysis shows that in two of the three selected schools a high number of students are already using a physically active travel mode to school. In contrast a private secondary school has more students who usually use a motorised travel mode. It can also be said that places for walking and cycling or the neighbourhood or community surroundings alone do not affect the decision on the travel mode. The decision on the travel mode to school stems from several different aspects, with the major influence being distance. If students live near the school or within a short walking or cycling time, it does not matter if there are negative responses about the neighbourhood surroundings as they use a physically active travel mode. These aspects become more and more important if the distance grows.

At the border between a physically active or a motorised travel mode where students are thinking if it is too far away or not, the neighbourhood surroundings or the accessibility of foot or cycle paths help to decide the travel mode. There are students living within a walking or cycling distance using a motorised travel mode and also students using a physically active travel mode. It is important that the parents let their children walk or cycle to school if they do not have to carry a lot. Getting a lift to school should be an exception and the last-resort. The produced maps provide information for decision makers for example about the bad maintenance of footpaths in many areas or the high appearance of litter in several areas of the study area for example. The maps provide information on how to help to increase the amount of students using a physically active travel mode to school. A particular advantage of this approach is that it allows a visual comparison of groups of students who live the same distance away from the school as others, but who don't use a method of active travel because of specific neighbourhood characteristics. There is a suggestion from this research that parents of children at private schools are more likely to drive them short distances to schools; this requires processing further schools in the study to establish if this is more widespread.

\section{Acknowledgments}

Stefan Schabus would like to acknowledge the support of the Centre for Health Geoinformatics at the National University of Ireland Maynooth, who hosted his internship. Particular thanks to Walter French who introduced him to the Irish address system and geocoding. Further Stefan Schabus would like to thank Catherine Woods of the Dublin City University who provided and supported him with the survey data of the CSPPA study. 


\section{References}

Blair, S. N., ChEnG, Y. \& Holder, J. (2001), Is physical activity or physical fitness more important in defining health benefits. Medicine and Science in Sports and Exercises, 33 (6), 379-399.

Craggs, C., Sluijs, E., Corder, K., Jones, A., Panter, J. \& Griffin, S. (2011), Do children's individual correlates of physical activity differ by home setting? Health \& Place, 17 (5), 1105-1112.

Diamond, L. J. \& Plattner, M. F. (2006), A Global Snapshot. Electoral Systems and Democracy, 1, 16-26.

Evans, E. (2000), Bally and Booley. Irish Folk Ways, 2, 27-38.

FAHEY, D. \& FINCH, F. (2011), GeoDirectory Technical Guide. GeoDirectory, 9.3, 1-66.

Fotheringham, S. A., Foley, P. F. \& Charlton, M. (2008), Automated Boundary Creation: Atomic Small Areas in Ireland. The European Information Society, 1, 241-260.

Jones, A., Sluijs, E., Ness, A., Haynes, R. \& RidDOCH, C. (2010), Physical activity in children: Does how we define neighbourhood matter? Health \& Place, 16 (2), 236-241.

Lewis, P., Fotheringham, A. S., Charlton, M. \& Winstanley, A. (2006), Mapping Psychiatric Address Data. Geographical Information Systems Research UK 2006, 1, 131-135.

Maffeis, C., Sluijs, E. \& Castellani, M. (2007), Physical activity: An effective way to control weight in children? Nutrition, Metabolism and Cardiovascular Diseases, 17 (5), 394-408.

O’Malley, P., Johnston, L. D., Delva, J. \& Terry-McElrath, Y. (2009), School Physical Activity Environment Related to Student Obesity and Activity: A National Study of Schools and Students. Journal of Adolescent Health, 45, 71-81.

Owen, N., Humpel, N., Leslie, E., Bauman, A. \& Sallis, J. F. (2004), Understanding environmental influences on walking; review and research agenda. American Journal of Preventive Medicine, 27, 67-76.

SAlmon, J. \& Timperio, A. (2007), Prevalence, trends and environmental influences on child and youth physical activity. Medicine and Science in Sports and Exercises, 50, 183-199.

Verstraete, S. J. M., Cardon, G. M., De ClercQ, D. L. R. \& De Bourdeaudhuij, I. M. M. (2006), Increasing children's physical activity levels during recess periods in elementary schools: the effects of providing game equipment. European Journal of Public Health, 16, 415-419.

Whitelaw, S., Teuton, J., Swift, J. \& Scobie, G. (2010), The physical activity - mental wellbeing association in young people: A case study in dealing with a complex public health topic using a ,realistic evaluation ${ }^{\text {ee }}$ framework, Mental Health and Physical Activity, 3, 61-66.

Woods, C. B., Tannehill, D., Quinlan, A. \& Moyna, N. \& Walsh, J. (2010), The Children`s Sport Participation and Physical Activity Study. Research Report No 1. School of Health and Human Performance, Dublin City University and the Irish Sports Council, Dublin, Ireland. 